\title{
Assessment of coastal management options by means of multilayered ecosystem models
}

Nobre, Ana M. ${ }^{1 *}$, Ferreira, João G. ${ }^{1}$, Nunes, João P. ${ }^{2}$, Yan, Xiaojun. ${ }^{3}$, Bricker, Suzanne ${ }^{4}$, Corner, Richard ${ }^{5}$, Groom, Steve ${ }^{6}$, Gu, Haifeng ${ }^{7}$, Hawkins, Anthony J.S. ${ }^{6}$, Hutson, Rory ${ }^{6}$, Lan, Dongzhao ${ }^{7}$, Lencart e Silva, João D. ${ }^{8}$, Pascoe, Philip ${ }^{6}$, Telfer, Trevor ${ }^{5}$, Zhang, Xuelei ${ }^{9}$, Zhu, Mingyuan ${ }^{9}$

${ }^{1}$ Institute of Marine Research (IMAR), Centre for Ocean and Environment, New University of Lisbon. DCEA. FCT, Campus da Caparica, 2829-516 Caparica, Portugal

*ana@salum.net; Phone: +35121294 8397 (X 10117); Fax: +35121294 8554.

${ }^{2}$ CESAM \& Department of Environment and Planning, University of Aveiro. Campus Universitário de Santiago, 3810-193 Aveiro, Portugal

${ }^{3}$ Marine Biotechnology Laboratory, Ningbo University, Ningbo 315211, P.R. China

${ }^{4}$ NOAA-National Ocean Service, National Centers for Coastal Ocean Science, 1305 East West Highway, Silver Spring, MD 20910, USA

${ }^{5}$ Institute of Aquaculture, University of Stirling, Stirling, FK9 4LA, United Kingdom

${ }^{6}$ Plymouth Marine Laboratory, Prospect Place, The Hoe, Plymouth PL1 3DH, Devon, United Kingdom

${ }^{7}$ Third Institute of Oceanography, Xiamen, 361005, P.R. China

${ }^{8}$ CESAM \& Department of Physics, University of Aveiro. Campus Universitário de Santiago, 3810193 Aveiro, Portugal

${ }^{9}$ First Institute of Oceanography, 6 Xianxialing Road, Qingdao 266061, P.R. China 


\section{Abstract}

This paper presents a multilayered ecosystem modelling approach that combines the simulation of the biogeochemistry of a coastal ecosystem with the simulation of its main forcing functions such as catchment loading and aquaculture activities. This modelling approach was developed as a tool for the sustainable management of coastal ecosystems. A key feature is to simulate management scenarios that account for changes in multiple uses and enable assessment of cumulative impacts of coastal activities. The model was applied to a coastal zone in China with large aquaculture production and multiple catchment uses, and where management efforts to improve water quality are under way. Development scenarios designed together with local managers and aquaculture producers include the reduction of fish cages and treatment of wastewater. Despite the reduction in nutrient loading simulated in three different scenarios, inorganic nutrient concentrations in the bay still exceed the thresholds for poor quality according to the Chinese seawater quality standards. There are still other management options to be considered given that for any of the scenarios there is still a moderate high to high portion of nutrient loads from the catchment and fish cages that can be reduced. The model predicts that overall, shellfish production decreases using any of these development scenarios (less $10 \%$ to $28 \%$ ). Main reason is that shellfish growth is being sustained by the substances to be reduced for improvement of water quality. To counteract this effect the model outcomes indicate that zoning of shellfish aquaculture should be implemented at the ecosystem level to optimize productivity ratios. The present case study exemplified the value of multilayered ecosystem modelling as a tool for Integrated Coastal Zone Management and for the adoption of ecosystem approaches for marine resource management. This modelling approach can be applied worldwide, and maybe particularly useful for the application of coastal management regulation, such as in implementing the European Marine Strategy Directive. 


\section{Keywords}

Integrated Coastal Zone Management; Ecosystem Management; Multilayered ecosystem modelling;

Catchment-coastal modelling; Sustainable aquaculture; China, Zhejiang, Xiangshan Gang. 


\section{Introduction}

Coastal zones provide considerable benefits to society while at the same time human activities exert pressure on coastal ecosystems, therefore threatening those same benefits (Nobre, In press). To promote the sustainable use of coastal zone resources an ecosystem approach is of considerable value, firstly in understanding the causal relationships between the environmental and socio-economic systems, and the cumulative impacts of the range of activities developed in coastal ecosystems (Soto et al., 2008; Nobre and Ferreira, 2009); and secondly to manage coastal resources and biodiversity (Browman and Stergiou, 2005; Murawski et al., 2008). Marine Ecosystem-Based Management (EBM) is an emerging scientific consensus complementary to Integrated Coastal Zone Management (ICZM). EBM highlights the need to use the best available knowledge about the ecosystem in order to manage marine resources with an emphasis on maintaining ecosystem service functions (Browman and Stergiou, 2005; Murawski, 2007; Murawski et al., 2008). In particular, improved planning and management of aquaculture production is highlighted as one of the sustainability issues related to coastal zone development and management that must urgently be addressed (GESAMP, 2001). Recently, several initiatives have occurred to support the development of an Ecosystem Approach to Aquaculture (EAA), which aims to integrate aquaculture within the wider ecosystem in order to promote the sustainability of the industry (Soto et al., 2008).

Ecosystem modelling is a powerful tool that can contribute the required scientific grounding for the adoption of such Ecosystem-Based Management approach (Fulton et al., 2003; Greiner, 2004; Hardman-Mountford et al., 2005; Murawski, 2007). Specifically, modelling can be useful to (i) provide insights about ecological interactions within the ecosystem in cases where extensive field work is not an option (Raillard and Ménesguen, 1994; Plus et al., 2003; Dowd, 2005; Grant et al., 2008; Sohma et al., 2008; Dumbauld et al., 2009), (ii) estimate the cumulative impacts of the several activities operating on a given ecosystem at an integrated catchment - 'marine ecosystem' 
scale (Soto et al., 2008), and (iii) evaluate the susceptibility of an ecosystem to pressures by means of scenario simulation (Hofmann et al., 2005; Nobre et al., 2005; Roebeling et al., 2005; Marinov et al., 2007; Ferreira et al., 2008a). James (2002), Fulton et al. (2003), and Moll and Radach (2003) reviewed several examples of ecological models used in the simulation of the hydrodynamics and biogeochemistry of aquatic ecosystems. The models used vary widely according to their target application. For instance, aquaculture related models can be developed at the farm scale (e.g. Cromey et al. 2009; Ferreira et al. 2007) or at the ecosystem scale (e.g. Dowd 2005; Ferreira et al., 2008a). These models can focus on specific features of the environment such as seston biodeposition (Cromey et al. 2009; Weise et al., 2009), or can integrate the ecosystem biogeochemistry (Plus et al., 2003; Dowd, 2005; Grant et al., 2008; Ferreira et al., 2008a). Ecological models can also focus on how the environmental parameters affect the physiology of cultured species (e.g. Gangnery et al., 2004; Raillard and Ménesguen, 1994) or how aquaculture production affects the wider ecosystem (e.g. Grant et al. 2008; Weise et al. 2009). The role of models to evaluate the 'disturbances' caused by bivalve mariculture on coastal systems may be especially important in the USA where increasing regulations in some cases are being implemented on the basis of the precautionary principle, with a consequent restriction of aquaculture activities (Dumbauld et al., 2009). Other parallel major effort related to coastal model development is the simulation of the interactions between catchment and coast, for instance the work developed under the EuroCat ('European catchments, catchment changes and their impact on the coast') research project (Salomons and Turner 2005). The work presented by Artioli et al. (2005), Hofmann et al. (2005) and Nikolaidis et al. (2009) exemplify the existing modelling approaches including the interface between the biophysical and socio-economic models for the catchment and coastal systems.

Overall, if a model is to contribute to an Ecosystem-Based Management approach, it should integrate the range of processes that interact and thus allow simulation of the resulting cumulative impacts. For instance, a model to assist in the determination of ecological carrying capacity of 
aquaculture production must include inputs from the multiple aquaculture farms situated in a given ecosystem and include simulation of other relevant coastal activities, for example those within the catchment area (Soto et al., 2008). Additionally, and particularly important for management, is the use of models for scenario simulation (Roebeling et al., 2005). This practice implies that management-relevant scenarios are developed to test changes in multiple uses or to explore impacts of global environmental changes (Hofmann et al., 2005; Nobre et al., 2005; Marinov et al., 2007; Ferreira et al., 2008a). This type of approach is crucial for EBM and requires close interaction with managers, decision-makers, and ecosystem and resource users (Ledoux et al., 2005; Nunneri and Hofmann 2005). In addition, ecosystem stakeholders must be able to understand the information that models provide and also contribute information on the issues to be managed, so that model development addresses their particular needs. Existing modelling tools have already proven useful in supporting the application and implementation of several legislative and management programmes worldwide as exemplified in Table 1.

Table 1 here.

Ongoing research (Raick et al. 2006) is investigating trade-offs between (i) increasingly complex models that provide detailed simulations but require large datasets for model setup/validation (e.g. developed by Marinov et al., 2007) and generate outputs which are difficult to synthesise; and (ii) simple models that due to generalisation of processes or resolution may fail to simulate important ecosystem features (e.g. McKindsey et al., 2006). There is also an intermediate approach, whereby different models running at different scales can be integrated in order to optimise the trade-offs between complex and simple models (Ferreira et al., 2008a). Model integration can be implemented for instance by (i) coupling offline upscaled outputs of detailed hydrodynamic models with ecological box models (Raillard and Ménesguen, 1994; Nobre et al., 2005; Ferreira et al., 2008a); or (ii) explicitly integrating models with different time steps, particularly important if there is a need to take into account feedback between the models, as is the case of ecological-economic simulations 
(Nobre et al., In press). The advantages of the intermediate approach include: (i) running multi-year ecosystem models without the computational limitations reported for detailed models (Grant et al., 2008); (ii) fewer data requirements for model setup (Ferreira et al., 2008a); and (iii) running coarser models at the end of the modelling chain, that present a higher level of information, which are more suitable to inform managers (Ferreira et al., 2008a). The development of integrative tools that simulate the catchment and the biogeochemistry of coastal waters, including cultivated species, is at an early stage, and there are only a few such simulations of management scenarios at the catchment-coastal scale (e.g., Marinov et al., 2007; Ferreira et al. 2008b).

Here we present a multilayered catchment-coastal modelling approach that uses a comprehensive set of models operating at different levels of complexity and geographical scales in order to optimize the trade-offs between complex and simple models. China provides an opportunity for an emblematic case study, given that its coastal areas exhibit a rapid economic growth (10\% average increase of GDP over 1995-2005), which is causing conflict among its multiple uses (Cao and Wong, 2007). Furthermore, according to data from FAO (undated) Chinese shellfish aquaculture production (including clams, cockles, arkshells, mussels, oysters and scallops) increased at an average annual rate of about $28 \%$ since 1990 , and in 2007 represented $77 \%$ of the world's shellfish production. Therefore, integrated management of the Chinese coastal zone is a considerable challenge requiring a comprehensive management scheme (Cao and Wong, 2007). The key features of the approach presented here are to: (i) integrate a set of tools at the catchment-coastal scale, and (ii) engage the aquaculture producers, local fishery and environmental managers in the modelling process. The improvements generated by this approach are to allow the examination of different development scenarios by altering variables of both the catchment and coastal systems and to provide insights for managers. These are critical developments for ICZM and EAA given that such models allow for the assessment of cumulative impacts of coastal activities at the ecosystem level. The specific objectives of this work are to: (i) develop an integrated coastal management tool 
for decision-makers; (ii) examine the outcomes of different development scenarios; and (iii) review the consequences of different monitoring options with respect to model outputs.

\section{Methodology}

\subsection{Study site and data}

A Chinese bay, the Xiangshan Gang (Figure 1) was chosen as a case study for the following reasons: (i) it encompasses multiple uses of the marine ecosystem and catchment area; (ii) it is illustrative of Southeast Asian systems and of European and North American systems at a larger scale of coastal resource uses; (iii) it has proactive stakeholders and management; and (iv) there is access to data. The Xiangshan Gang is a long bay (ca. $60 \mathrm{~km}$ in length) connected to the East China Sea, with slow flushing rates in the inner bay and middle section of about 80 and 60 days, respectively, for $90 \%$ water exchange, and a more rapid exchange rate at the mouth of about 7 days for $90 \%$ water exchange (Huang et al., 2003). This embayment has an intensive aquaculture production of shellfish and finfish and is located in an industrialised area South of Shanghai in Northern Zhejiang Province. The aquaculture resources produced in Xiangshan Gang have changed considerably over time (Ning and Hu, 2002). In 1987 there was only kelp cultivation. Molluscan shellfish and shrimp aquaculture were introduced in the first half of the 1990's. However, due to high shrimp mortalities farmers introduced razor clams in ponds. In this way, farmers leveraged the bivalves' ability to remove particulate waste while producing an additional cash crop in an Integrated Multi-Trophic Aquaculture (IMTA) system. During the second half of the 1990's finfish aquaculture increased considerably. In 1998 the fish cages in the bay were estimated as 18 000, increasing to 67000 in 2002 . Emerging water quality problems in the bay have been associated with the rapid increase in finfish aquaculture: (i) research programmes executed in 2002 measured anoxic layers with an average depth of $20-30 \mathrm{~cm}$ and a maximum depth of $80 \mathrm{~cm}$ (Ning and $\mathrm{Hu}, 2002$; Huang et al., 2008b); (ii) 21 occurrences of harmful algal blooms (HAB) were 
recorded in 2003 in Xiangshan Gang and the nearby sea area, including 3 occurrences inside the bay that lasted for more than 30 days (SOA, 2006; Zhang et al., 2007). In 2003, local decisionmakers reduced the number of the fish cages by $30 \%$ (NOFB, 2007) in an attempt to address those environmental problems. Estimates for Xiangshan aquaculture production in 2005-2006 include: 45 000 t shellfish year $^{-1}$ of which $93 \%$ is Ostrea plicatula (Chinese oyster) produced either on ropes or in intertidal areas; $9400 \mathrm{t}_{\text {finfish year }}^{-1}$; and pond production of shrimp, crabs and clams $(6700 \mathrm{t}$ year $\left.^{-1}\right)$.

Figure 1 here.

A detailed description of the bay and its catchment can be found in Ferreira et al. (2008b). Table 2 shows a synthesis of the data collated and used in this paper. Data sources included available historical and web-based data complemented by a limited sampling program collected under the EU SPEAR project ("Sustainable options for PEople, catchment and Aquatic Resources”, Ferreira et al., $2008 b)$ to fulfil the data requirements for modelling. Remote sensing was used to provide extensive spatial data, namely catchment land use and aquaculture structure mapping (Table 2).

Table 2 here.

Water quality data was assimilated into a relational database, which was used for retrieval of data for ecosystem model setup and evaluation. A geographic information system (GIS - ArcGIS ${ }^{\mathrm{TM}}$ ) was used to store and analyse spatial data, to produce thematic maps and generate information for model setup.

\subsection{Multilayered ecosystem model}

An integrated ecosystem modelling approach was used (Ferreira et al. 2008b) to simulate the hydrodynamics, biogeochemistry, aquaculture production and forcing functions, such as catchment 
loading, within Xiangshan Gang. The multilayered approach includes the coupling of several submodels (Ferreira et al. 2008b) and ecosystem-based tools, as shown in Figure 2.

Figure 2 here.

The EcoWin2000 modelling platform (Ferreira, 1995) was used to integrate, implicitly or explicitly, all the sub-models and thus to run the multilayered ecosystem model. The spatial domain of the Xiangshan Gang model was divided into 12 horizontal boxes and vertically into 2 boxes (Figure 1). The division into boxes followed the procedure described in Ferreira et al. (2006) and included a range of criteria: hydrodynamics, catchment loads, water quality and aquaculture structure distribution. The EcoWin2000 was set up using a combination of measured data (water quality and aquaculture practice among others) and model outputs (for transport of substances inside the system, from the catchment and exchanged with the sea), as depicted in Figure 2. The implementation of each sub-model is detailed below and the main equations for state variables are presented in Table 3.

Table 3 here.

Table 4 and Table 5 specify the ecosystem model forcing functions and parameters. The model was run, using a time step of one hour, for the calibration year (2004), the validation year (standard simulation - June 2005 to June 2006) and a set of different scenarios.

Table 4 and Table 5 here.

\subsubsection{Catchment sub-model}

The substance loading from the adjacent watershed was forced using estimates obtained from the Soil and Water Assessment Tool (SWAT) model (Neitsch et al., 2002). The model was applied to Xiangshan Gang catchment area using data indicated in Table 2. The model was calibrated against annual average discharge estimates for the most important rivers in the catchment, using a 30-year 
model run for a synthetic climate based on the 1961-90 climatic normal, built with the model's stochastic weather generator. Model performance for water inputs was satisfactory, as indicated by a significant correlation between simulated and observed values $\left(r^{2}=0.92\right)$, low model bias $(-5.3 \%)$ and high model efficiency (Nash-Sutcliffe efficiency index $=0.91$ ). Simulated annual nitrogen inputs from diffuse agricultural sources (960 $\mathrm{t}_{\text {year }}^{-1}$ ) compared well with an estimate by Huang et al. (2008b) based on export coefficients (900 t year $\left.{ }^{-1}\right)$. After being evaluated, the model was run for the study period (2004-2006) using climate data described in Table 2. The output from the SWAT model simulation was transformed into daily data series aggregated per box for offline coupling with EcoWin2000 (for both calibration and validation years). In total, the nutrient load entering the bay from the catchment consisted of about $11 \mathrm{t} \mathrm{d}^{-1}$ of dissolved inorganic nitrogen and $2 \mathrm{t} \mathrm{d}^{-1}$ of phosphate. Whereby, $30 \%$ of the total loads were diffuse pollution from agriculture and forest litter decomposition. The point sources included untreated urban wastewater for ca. 600000 inhabitants.

\subsubsection{Hydrodynamic sub-model}

The transport of substances among boxes and across the ocean boundary was simulated using the upscaled outputs of a detailed three-dimensional hydrodynamic and transport model (Delft3D-Flow Delft Hydraulics, 2006) (Ferreira et al., 2008b). Delft3D-Flow is well tested software used to generate highly detailed continuous flow fields (Delft Hydraulics, 2006). The model calibration was performed in two major phases. In the first phase, only tidal forcing was used. Variations in tidal forcing were compared against measured water levels to achieve an optimum in harmonic composition of the tidal elevation, followed by adjustment of bottom roughness to reproduce the water velocity characteristics reported by Huang et al. (2003). In the second phase a baroclinic model was developed by including heat and freshwater contributions. In order to define the model boundary conditions, the salinity and temperature dataset was complemented with data from Hur et al. (1999) and Isobe et al. (2004). In this second phase the response of the system was gauged upon existing knowledge of circulation as effected by tides and baroclinicity in tidal embayments 
(Simpson, 1997; Fujiwara et al., 1997). Due to the lack of in situ density and velocity measurements, this procedure was used to tune the model within the theoretically acceptable boundaries for this type of system. The model outputs provided a repeatable series of approximately 1 year of flows with which to force transport in the ecosystem model for both the calibration and validation years. The data series length was chosen in order to be as close to an annual cycle (365 days) as possible in terms of fortnightly lunar cycles. Therefore, the series obtained was 3 days and 10 hours longer for 2004. The resulting residual surplus $\left(0.1 \mathrm{~m}^{3} \mathrm{~s}^{-1}\right.$ averaged over the bay and $0.7 \mathrm{~m}^{3} \mathrm{~s}^{-1}$ at a single box) was artificially subtracted in order to ensure the conservation of the mass. The detailed flow fields were scaled up and converted into a data series of water fluxes between boxes and across the sea boundary with a one hour time step and coupled offline with EcoWin2000 (see e.g. Ferreira et al. 2008a).

\subsubsection{Aquatic resource sub-model}

The simulated aquatic resources included Ostrea plicatula (Chinese oyster), Sinonvacula constricta (razor clam), Tapes philippinarum (Manila clam) and Tegillarca granosa (muddy clam) production. The equations for shellfish aquaculture production were explicitly integrated into the ecosystem model using a four step approach (Ferreira et al., 2008a): (i) use of a shellfish individual growth model (ShellSIM - http://www.shellsim.com); (ii) coupling of the individual growth model with a demographic model to simulate the population; (iii) integration of the population growth model with an aquaculture practice model which implements the seeding of the population biomass and harvesting of the marketable cohorts for a given production cycle; and (iv) use of a multipleinheritance object-oriented approach (Nunes et al., 2003) to extend to multiple species in polyculture. ShellSIM simulates feeding, metabolism and individual growth in contrasting environments for different shellfish species, as exemplified for Chlamys farreri by Hawkins et al. (2002). The individual growth model was calibrated for the four species under local conditions (Ferreira et al., 2008b). The population and aquaculture practice models are described in previous 
modelling applications to simulate aquatic resources at the ecosystem scale (Ferreira et al., 2008a). A synthesis of model parameterization is presented in Table 4.

Both shrimp and fish production were included as forcing functions of the ecosystem model, contributing to dissolved and particulate waste (Ferreira et al. 2008b). The annual fish cage loadings to the Xiangshan Gang (Table 4) were calculated based on the number of fish cages per box; average fish production per cage; food waste; and nutrient load per fish produced, based on dry feed conversion rate (Cai and Sun, 2007). Nutrient loads from the shrimp ponds (Table 4) were calculated by means of a shrimp growth model (LMPrawn) as described in Ferreira et al. (2008b) and Franco et al. (2006).

\subsubsection{Biogeochemical sub-model}

The biogeochemical model was developed using EcoWin2000 to simulate the concentration of dissolved substances, particulate matter and phytoplankton, and to simulate the solar radiation and water temperature forcing functions (Ferreira, 1995; Nunes et al., 2003; Nobre et al., 2005; Ferreira et al., 2008b). Simulated dissolved inorganic nitrogen (DIN) and phosphate concentrations were used for calculation of the nutrient limiting phytoplankton growth. The sub-models described above were used to simulate the shellfish aquaculture production, the catchment loads, and the transport of water and substances between boxes and across the sea boundary. Ocean boundary conditions and atmospheric loadings were derived from historical data and defined as annual average values. Due to the lack of synoptic data for the setup of the ocean boundary, sea water quality data for 2002 was used for both the calibration and validation model runs. Seasonal data for nutrients contained in the rain water were used to determine the average annual loads of nitrogen $(N)$ and phosphorus $(P)$ to the bay. The parameterization of the model for Xiangshan Gang is presented in Table 4 .

The pelagic variables in the model were calibrated against a historical time series for 2004 (Table 2). Due to lack of historical data, the annual average of the validation year was used for suspended 
particulate matter (SPM) and particulate organic matter (POM). The model was run for the validation year using the same parameters employed for the calibration year but changing the forcing functions and initial variables to simulate the period from June 2005 to June 2006. Model performance was evaluated by comparing the model outputs of the standard simulation with the water quality and aquaculture production data for the validation period.

\subsection{Coastal management options simulation}

\subsubsection{Definition of development scenarios}

The development scenarios were defined as a result of the participatory work among stakeholders carried out during the SPEAR project (Ferreira et al., 2008b). Several stakeholder meetings were held involving modellers, local fishery and environmental managers and aquaculture producers. The capabilities of the modelling tools to support catchment and aquaculture management were explained to the local managers and producers. In addition, the issues of concern to the local managers and producers were discussed with the modelling team. The participatory work among stakeholders culminated with a clear set of scenarios defined by the Xiangshan Gang managers and aquaculture producers. The scenarios to be simulated by the multilayered ecosystem modelling framework comprised of: (i) a reduction of fish cages corresponding to $38 \%$ reduction in total fish production (Scenario 1); (ii) an extension of wastewater treatment to the entire population (Scenario 2); and (iii) a simultaneous reduction of fish cages and extended wastewater treatment (Scenario 3). These scenarios are important for the evaluation of nutrient abatement strategies defined by managers to improve water quality in Xiangshan Gang. From a management perspective, the scientific assessment of such scenarios will also provide guidelines/groundings for future aquaculture policy and for eutrophication control.

\subsubsection{Development scenario implementation and interpretation}


The reduction of fish cages (scenarios 1 and 3) was implemented assuming that the decrease in nutrient loading is proportional to the decrease in fish production. The impact of wastewater treatment (scenarios 2 and 3 ) on the exports of N, P and sediment from urban areas was calculated following Burks and Minnis (1994). Table 6 synthesises the corresponding substance loading used to simulate each scenario.

A comparison of the results obtained for the different scenarios was performed and the interpretation of the outcomes was guided by means of (i) Influencing Factors (IF) from the ASSETS eutrophication model (Bricker et al., 2003) to interpret the influence of catchment and aquaculture loads on eutrophication; (ii) threshold of chl-a 90-percentile values as defined in the ASSETS model (Bricker et al. 2003) to assess the level of expression of the phytoplankton symptom; and (iii) Chinese sea water quality standards (National Standard of People's Republic of China, 1997) for DIN and phosphate to assess the compliance with desirable water quality objectives set by decision-makers for the bay.

\subsubsection{Evaluation of monitoring options}

Coastal ecosystem model development implies monitoring of substance loadings from the adjacent catchment area. However, this is often restricted to a few locations within the watershed and to a few sampling occasions over the year. In this work the use of SWAT model enabled the application of detailed forcing in space and time for catchment loads using limited sampling, and allowed testing the consequences of different monitoring options on simulated results; this was done by running the standard simulation using monthly, rather than of daily, data series of the catchment model outputs. 


\section{Results}

\subsection{Standard simulation}

Figure 3 shows catchment model results for runoff and $\mathrm{N}$ loading into Xiangshan Gang, from diffuse (agricultural) and point (urban sewage) sources. $\mathrm{N}$ inputs have two annual peaks, in early spring and early summer, which can be related with both the fertilization of rice (which is harvested twice per year in this region) and the annual rainfall and runoff patterns. This pattern was also found for particulate matter and P loads. The large input peak in August 2005 is an exceptional occurrence which was mostly caused by typhoon Matsa in August 5. The major sources for N, according to the model results are urban sewage discharges (56\%); agricultural, namely fertilization in rice crops (27\%); and rangelands, mostly vegetation detritus decomposition in forests (17\%). P followed a similar pattern, with $60 \%$ coming from urban sewage discharge and the remainder from agricultural and natural sources.

Figure 3 here

Figure 4 shows the coastal ecosystem model results for the pelagic variables in an inner location (Box 3) and a location in the middle of the bay (Box 10). The ecosystem model outputs for DIN and phytoplankton compare well with collected data, as exemplified for boxes 3 and 10 in Figure 4. The DIN peak observed around day 120 in Box 3 is not reproduced, possibly due to an underestimation of the loads for that period (from catchment or from aquaculture) or due to a local phenomenon that does not represent the average for the box. In contrast, the model outputs for phytoplankton exhibit peaks not seen in the data. In particular, the sampling point immediately before day 180 shows a very low value for phytoplankton, whereas the model simulates high phytoplankton concentrations. A combination of three factors can justify this occurrence: (i) high natural variability of phytoplankton (Rantajärvi et al., 1998); (ii) phytoplankton dynamics are ruled by complex set of factors difficult to simulate in dynamic ecological models, such as species succession (Arhonditsis et al., 2007); and 
(iii) the model outputs represent an uniform value for a box, thus cannot account for the variability in that area. With regard to phosphate, the data did not indicate a particular pattern, and in general the model overestimated observed phosphate concentrations. Model outputs of SPM and POM in Box 10 did not represent the observed variability whereas in the inner box (Box 3 ) the model outputs reproduced the trends shown by the data points (Figure 4). A possible explanation is that the temporal resolution of SPM and POM values being used to force the ocean boundary was not enough to represent the variability in the adjacent boxes. As such, a timeseries should be used instead of the annual average ocean concentration. In the inner boxes the marine influence was reduced and catchment inputs of POM and SPM were more important, thus the daily inputs provided by the catchment model provided the appropriate forcing. Nevertheless, this limitation is not likely to significantly affect the simulation of aquaculture production, given that $83 \%$ of the bivalves are produced in the inner boxes (boxes 1 to 5 ).

Figure 4 here

Figure 5 shows the simulation of shellfish production, using oysters as an example for this species account for $93 \%$ of total shellfish production, and the respective key environmental drivers for shellfish growth. Figure 5 also shows the mass loss calculated based on the net energy lost due to physiological processes. The energy balance accounts for the energy ingested, energy lost as faeces, energy excreted, the heat loss and the energy loss due to reproduction (Ferreira et al., 2008b). Model results are present for an inner box (Box 3) with total shellfish production of ca. 2305 $\mathrm{t}$ (oysters account for ca. $1298 \mathrm{t}$ ) and a box near the sea boundary (Box 11) with a total shellfish production of ca. $741 \mathrm{t}$ (all oyster). The oyster standing stock was generally higher in Box 11 than in Box 3, possibly due to the higher POM availability registered in most part of the year in Box 11 (Figure 5). As a result, POM uptake by oysters was about six-fold higher in Box 11 (3.36 $\mathrm{g} \mathrm{m}^{-2}$ year $^{-1}$ ) than in Box $3\left(0.54 \mathrm{~g} \mathrm{~m}^{-2}\right.$ year $\left.^{-1}\right)$. The effects of the peaks of phytoplankton concentration in Box 3 around days 120 and 180 (peaks P2 and P3, respectively, Figure 5) are visible by the increase of 
the shellfish biomass and standing stock. This effect was not visible for the smaller peak that occurs after day 240 (peak P4, Figure 5), because it was neutralized by the mass lost due to physiological processes (ML4, Figure 5) possibly caused by the high temperatures that occur during the ML4 period (Figure 5). On average, phytoplankton concentration was higher in Box 3: annual average

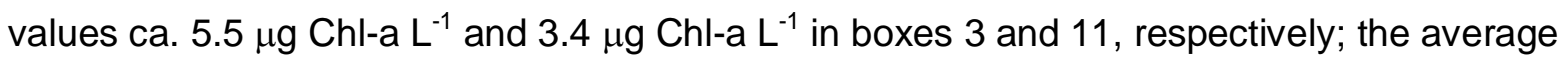
phytoplankton uptake was also higher in Box 3: ca. $38.6 \mathrm{~g} \mathrm{C} \mathrm{m}^{-2}$ year $^{-1}$ and $36.0 \mathrm{~g} \mathrm{C} \mathrm{m}^{-2}$ year $^{-1}$ in boxes 3 and 11, respectively. Possibly, these differences of phytoplankton uptake among both boxes were much smaller than differences in POM uptake given that higher phytoplankton availability in Box 3 was counteracted with a higher shellfish production in that box which led to the partitioning of resources among cultivated animals (Figure 6).

Figure 5 here

Overall, the outputs of harvested shellfish compare well with the survey data (Figure 6).

Figure 6 here

\subsection{Development scenarios}

The scenarios tested simulate different nutrient loads entering into the bay. Table 6 presents the $\mathrm{N}$, $\mathrm{P}$ and POM loading into the bay from catchment and aquaculture sources for each scenario. The Influencing Factors (IF) from aquaculture and catchment loads on the bay's nutrient concentration ranged from $75 \%$ in the standard simulation to $70 \%$ for scenario 3 , for $\mathrm{N}$ (Table 6 ). For $\mathrm{P}$ the contribution was higher ranging from $94 \%$ in the standard simulation to $90 \%$ in scenario 3 (Table 6 ). These results, according to the categories defined in the ASSETS model (Bricker et al. 2003), indicated that for $\mathrm{N}$ and $\mathrm{P}$ there was a "moderate high" and a "high" class, respectively, for the portion of nutrients from anthropogenic sources compared with those coming from the sea.

Therefore, there is the potential for a significant reduction of nutrients through management. The major contribution of nutrients for any of the scenarios tested was from catchment loading (Table 6). 
Table 6 here

In general, model outcomes indicate that the effects of changes implemented in the scenario simulations were mostly visible in the inner boxes. Figure 7 shows the model outputs for (i) an inner box (Box 3 - Huangdun Bay), where the reduction of fish cages (in scenarios 1 and 3, Table 6) and the reduction of nutrient loads from wastewater discharge (in scenarios 2 and 3, Table 6) were implemented; (ii) a middle box (Box6) where no direct changes were implemented; and (iii) an outer box (Box 12), where, as for Box 3 a reduction of fish cages and nutrient loads from wastewater was tested (Table 6). The changes simulated in the three scenarios were less evident for the outer box for DIN, phosphate, phytoplankton, shellfish harvest and productivity variables (Figure 7). This was possibly due to the exchanges with the ocean boundary. The reduction of nutrient loads in any of the scenarios resulted in very small changes in bay DIN concentration for any of the boxes (Figure 7a). There was a higher impact of nutrient load reduction on the simulated phosphate concentration (Figure $7 b$ ). Changes in phosphate concentration ranged from $-8 \%$ to $-21 \%$ in Box 3 and from $-2 \%$ to $-6 \%$ in Box 12 when comparing the scenarios with the standard simulation. Despite the fact that no direct changes were simulated in any of the scenarios for Box 6, model outputs (Figure 7b) also indicated changes of phosphate concentration (between $-6 \%$ and $-12 \%$ ), possibly as a result of the transport between boxes. Both DIN and phosphate were present in high concentrations and, on average phosphate was the limiting nutrient for the phytoplankton growth for every scenario and in every box. According to the Chinese seawater quality standards for nutrient concentration parameters (National Standard of People's Republic of China, 1997), water quality in Xiangshan Gang on average is classified as being above the limit of Class IV, meaning poor quality. This result was also confirmed by the sampled water quality data.

Figure 7 here

Regarding phytoplankton concentration, the most pronounced changes occurred in the inner boxes; in boxes 6 and 12 the effects of the nutrient load reduction were possibly dissipated (Figure 7c and 
d). Figure 7c shows the phytoplankton 90-percentile value for different boxes and scenarios. Considering thresholds defined in the ASSETS model, this symptom is classified as "medium" in Box 3 for any scenario. In the middle and outer boxes the phytoplankton concentrations were lower and 90-percentile values fell in the limit between the "low" and "medium" classes (e.g. boxes 6 and 12 in Figure 7b), possibly due to higher seawater renewal. For Box 6, the small decrease of phytoplankton due to nutrient load reduction resulted in a shift of phytoplankton 90-percentile value from "medium" in the standard scenario to "low" in any of the scenarios. In Box 12, for all the scenarios, the phytoplankton 90-percentile value falls within the "low" class.

Overall, the simulated actions had a limited impact on the bay water quality. There was an improvement of the chl-a level from "medium" to "low" with the implementation of every scenario in Box 6 and with implementation of scenarios 2 and 3 in Box 7. Regarding DIN concentration, there was a reduction in Box 8 following the implementation of every scenario, which lowers the ranking to Class IV (poor). There was also a reduction of phosphate concentration in Scenario 3 that lowers the classification of this variable to Class IV (poor) in boxes 6 and 10, and to Class II/III in Box 12.

For all scenarios, the model predicted a decrease of shellfish productivity measured as the ratio of harvest biomass to seeding biomass in each cultivated species when compared with the standard scenario (Figure 7f). Figure 7e indicates that the shellfish production decrease was more significant in the inner box (Box 3, 12-37\% corresponding to less $286-864 \mathrm{t}_{\text {year }}{ }^{-1}$ ), whereas in the outer box (Box 12) no significant changes occurred (0.1-0.2\% corresponding to less 8-16 t year $\left.{ }^{-1}\right)$. A more detailed examination of the shellfish productivities in each box and scenario (Figure 8) showed that in general productivity levels were lower in boxes 1 to 7 (inner) and higher in boxes 8 to 12 (outer).

Figure 8 here

\subsection{Effects of monitoring options}


Comparison of ecosystem model outputs using different temporal resolutions for the catchment loads (Figure 9) indicated that using monthly instead of daily catchment inputs led to significantly different outcomes, especially for the inner boxes (as illustrated for Box 3 in Figure 9). In general, observed peaks in DIN, phosphate, phytoplankton and POM could be reproduced by the biogeochemical model when the monthly SWAT inputs were used. As a consequence, for example,

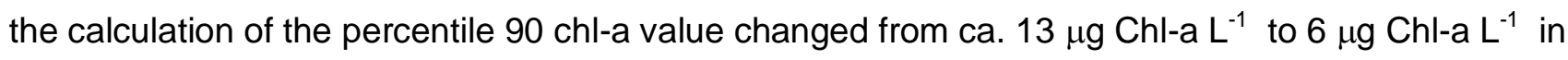

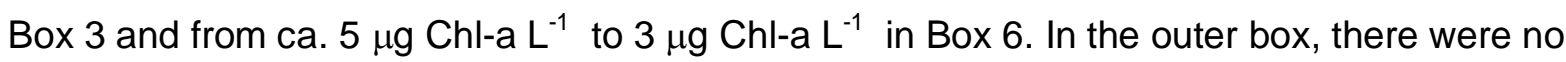
significant changes in the 90-Percentile chl-a value.

Figure 9 here

\section{Discussion}

The nutrient load reduction had no significant predicted effect on the Xiangshan Gang water quality according to Chinese Sea water quality thresholds for nitrate and phosphate. Improvements in phytoplankton concentration were limited to some areas of the bay. Therefore, the model suggests that the proposed scenarios will not lead to the management goals they were designed for. From an eutrophication perspective, remains a moderate high to high proportion of nutrient loads from the catchment and fish cages to Xiangshan Gang that can be managed. Future work using this multilayered ecosystem model includes the definition of further scenarios, using the SWAT model to assess how different land use management practices may impact the bay. Likewise, future scenarios might include the adoption of different aquaculture practices such as described by Ayer and Tyedmers (2009) to decrease the wastes from fish cages. The model outputs indicated that the nutrients and POM provided by fish cages and wastewater are sustaining shellfish growth in the inner boxes. In the scenarios that test a decrease of these substances (Table 5), shellfish production decreases (Figure 7e,f and Figure 8). The estimated total loss of harvested shellfish was between 4600 t year $^{-1}$ and 12700 t year $^{-1}$, corresponding to a relative decrease in the range of 10- 
$28 \%$. The reasons that those effects are predicted to be more evident in the inner section of the Xiangshan Gang include: (i) higher water residence times, in the range of 60 to 80 days; and (ii) higher competition for food resources given that cultivation areas in boxes 1 to 5 represented $89 \%$ of the total shellfish cultivation area, whereas these boxes accounted only for $34 \%$ of the total bay area. As such, and based on the analysis in Figure 8, it is advisable to reallocate part of the shellfish culture from the up- to downstream area of the embayment, in particular for the Chinese oyster and muddy clam. Such measures should be adopted in parallel to the reduction of substance loading into the bay in order to minimize the reduction in shellfish production. Notwithstanding, it is suggested that a cost-benefit analysis should be carried out to analyse the economic and environmental viability of alternative sources of income for the local community that might compensate for any decrease in aquaculture activities. A combined environmental and economic strategic assessment is even more important given that the Xiangshan Gang area is considered as a key area to promote sustainable development of the Ningbo municipality. Planning includes a balance between its protection and its use, to take advantage of ecological and marine resources (Ningbo Municipal People's Government, 2006). Expected uses include the entertainment and tourism industries, modern fishing and international logistics.

It is important to note that due to the complex nature of HAB causes and the chaotic behaviour of these events (Huppert, et al., 2005; Huang et al., 2008a), the simulation of HAB's is not included in the ecosystem model. HAB's represent a severe problem in the Xiangshan Gang and adjacent ocean as shown in Table 7. Whilst part of the observations indicates that many red tides originate in the East China Sea, some have developed inside the bay (Table 7). Severe economic losses were associated with these incidents either as a result of shellfish and finfish mortalities, due to toxic algae or to prohibited sale of seafood from the affected areas. The increase of HAB's in China (Table 7) may be associated with an increase of fish cages (Wang, 2002). Given the lack of knowledge about the causes of HAB's in Xiangshan Gang, it is speculative whether a reduction of nutrient discharge might cause a reduction of the occurrence of HAB's inside the bay and a 
consequent reduction in aquaculture closure time due to toxin contamination. For a clear understanding about the origin of the HAB's in the Xiangshan Gang, and thus about the management level of this issue, an analysis such as the one developed by Liu et al., (In press) could be undertaken.

Table 7 here

The comparison of ecosystem model results using different temporal resolutions for the catchment loads illustrate the importance of the SWAT catchment model in (i) providing a temporally distributed estimate of water and nutrient loadings from catchments into coastal systems, for different outlets; and (ii) evaluating the source of the nutrients useful for catchment management. Just as was tested for the dataset inputs, a temporally detailed data series of the ocean boundary conditions and of fish cage substance load inputs should be used to improve the model results, in particular for the downstream boxes of the bay.

\section{Conclusions}

The outcomes obtained for Xiangshan Gang indicate that the multilayered ecosystem model can play a key role in Integrated Coastal Zone Management (ICZM) and for the adoption of ecosystem approaches to marine resource management (EBM). The present case study also indicates that the integration of ecosystem-based tools minimize the field data requirements. The use of models to fill data gaps or improve the temporal/spatial detail of the setup datasets can be seen as a monitoring advantage to be implemented as a best practice for ecosystem modelling.

The multilayered ecosystem modelling approach is appropriate to support management of coastal and estuarine systems worldwide including the assessment of cumulative impacts of activities developed in these zones. Overall, the modelling approach presented in this paper can be helpful for the implementation of legislation and other regulatory instruments. For instance, it is a suitable 
tool for the implementation of the European Marine Strategy Framework Directive (Directive 2008/56/EC), namely for analysing scenarios designed to achieve the 'good environmental status' (GES). To maximize the potential usefulness of multilayered ecosystem models, a next step is to apply screening models and to couple ecology with socio-economics to provide more complete information to managers.

\section{Acknowledgments}

The authors are grateful to the EU project SPEAR - Sustainable options for PEople, catchment and Aquatic Resources (INCO-CT-2004-510706) for funding this research. Part of the work was supported by the Portuguese Foundation for Science and Technology (FCT) Ph.D. scholarship (SFRH/BD/25131/2005) to A.M. Nobre. The authors are grateful to C. Saurel for valuable comments.

\section{References}

Arhonditsis, G.B., Stow, C.A., Paerl, H.W., Valdes-Weaver, L.M., Steinberg, L.J. and Reckhow, K.H., 2007. Delineation of the role of nutrient dynamics and hydrologic forcing on phytoplankton patterns along a freshwater-marine continuum. Ecological Modelling 208, 230-246.

Artioli, Y., Bendoricchio, G., Palmeri, L., 2005. Defining and modelling the coastal zone affected by the Po river (Italy). Ecological Modelling 184, 55-68.

Ayer, N.W., Tyedmers, P.H., 2009. Assessing alternative aquaculture technologies: life cycle assessment of salmonid culture systems in Canada. Journal of Cleaner Production 17, 362-373.

Bald, J., Sinquin, A., Borja, A., Caill-Milly, N., Duclercq, B., Dang, C., de Montaudouin, X., 2009. A system dynamics model for the management of the Manila clam, Ruditapes philippinarum (Adams and Reeve, 1850) in the Bay of Arcachon (France). Ecological Modelling, In Press.

Batjes NH. 2002. Soil parameter estimates for the soil types of the world for use in global and regional modelling (version 2.1; July 2002). ISRIC report 2002/02c, International Food Policy Research Institute (IFPRI) e International Soil Reference and Information Centre (ISRIC), Wageningen. 
Borja, A., Bricker, S.B., Dauer, D.M., Demetriades, N.T., Ferreira, J.G., Forbes, A.T., Hutchings, P., Jia, X., Kenchington, R., Marques, J.C., Zhu, C., 2008. Overview of integrative tools and methods in assessing ecological integrity in estuarine and coastal systems worldwide. Marine Pollution Bulletin 56 1519-1537.

Bricker, S.B., Ferreira, J.G., Simas, T., 2003. An integrated methodology for assessment of estuarine trophic status. Ecological Modelling 169, 39-60.

Brock, T.D., 1981. Calculating solar radiation for ecological studies. Ecological Modelling 14, 1-9.

Browman, H.I. and Stergiou, K.I. (Eds.), 2005. Politics and socio-economics of ecosystem-based management of marine resources. Marine Ecology Progress Series 300, 241-296.

Burks BD, Minnis MM. 1994. Onsite Wastewater Treatment Systems. Hogarth House, Madison.

Cai H. and Y. Sun, 2007. Management of Marine Cage Aquaculture. Environmental Carrying Capacity Method Based on Dry Feed Conversion Rate. Environmental Science and Pollution Research 14, 463-469.

Cao, W., Wong, M. H., 2007. Current status of coastal zone issues and management in China: A review. Environment International 33, 985-992.

CGIAR, Consultative Group on International Agricultural Research. 2005. CGIAR-CSI SRTM 90m DEM Digital Elevation Database. Consortium for Spatial Information, Consultative Group on International Agricultural Research. Available online at: http://srtm.csi.cgiar.org/.

Cromey, C.J., Nickell, T.D., Treasurer, J., Black, K.D., Inall, M., 2009. Modelling the impact of cod (Gadus morhua L.) farming in the marine environment--CODMOD. Aquaculture 289, 42-53.

Delft Hydraulics, 2006. Delft3D-FLOW, a simulation program for hydrodynamic flows and transports in2 and 3 dimensions. User manual. Version 3.11.

Dowd, M., 2005. A bio-physical coastal ecosystem model for assessing environmental effects of marine bivalve aquaculture. Ecological Modelling 183, 323-346.

Dumbauld, B. R., Ruesink, J. L., Rumrill, S. S., 2009. The ecological role of bivalve shellfish aquaculture in the estuarine environment: A review with application to oyster and clam culture in West Coast (USA) estuaries. Aquaculture 290, 196-223.

Economopoulos AP. 1993. Assessment of Sources of Air, Water, and Land Pollution: A Guide to Rapid Source Inventory Techniques and Their Use in Formulating Environmental Control Strategies. World Health Organization, Geneva. 
FAO. Fishery statistical collections, Global aquaculture production 1950-2007. Available online: http://www.fao.org/fishery/statistics/global-aquaculture-production/en, searched on 6th May 2009.

Ferreira, J. G., Hawkins, A. J. S., Monteiro, P., Moore, H., Service, M., Pascoe, P. L., Ramos, L., Sequeira, A., 2008a. Integrated assessment of ecosystem-scale carrying capacity in shellfish growing areas. Aquaculture 275, 138-151.

Ferreira, J.G., Andersson, H.C., Corner, R.A., Desmit, X., Fang, Q., de Goede, E.D., Groom, S.B, Gu, H., Gustafsson, B.G., Hawkins, A.J.S., Hutson, R., Jiao, H., Lan, D., Lencart-Silva, J., Li, R., Liu, X., Luo, Q., Musango, J.K., Nobre, A.M., Nunes, J.P., Pascoe, P.L., Smits, J.G.C., Stigebrandt, A., Telfer, T.C., de Wit, M.P., Yan, X., Zhang, X.L., Zhang, Z., Zhu, M.Y., Zhu, C.B., Bricker, S.B., Xiao, Y., Xu, S., Nauen, C., Scalet, M., 2008b. SPEAR. Sustainable Options for People, Catchment and Aquatic Resources. IMAR-Institute of Marine Research. ISBN 978-972-99923-2-2. 184 pp.

Ferreira, J.G., Hawkins, A.J.S., Bricker, S.B., 2007. Management of productivity, environmental effects and profitability of shellfish aquaculture -- the Farm Aquaculture Resource Management (FARM) model. Aquaculture 264, 160-174.

Ferreira, J.G., Nobre, A.M., Simas, T.C., Silva, M.C., Newton, A., Bricker, S.B., Wolff, W.J., Stacey, P.E., Sequeira, A., 2006. A methodology for defining homogeneous water bodies in estuaries Application to the transitional systems of the EU Water Framework Directive. Estuarine, Coastal and Shelf Science 66, 468-482.

Ferreira J. G., 1995. ECOWIN - an object-oriented ecological model for aquatic ecosystems. Ecological Modelling 79, 21-34.

Franco, A.R., Ferreira, J.G., Nobre, A.M., 2006. Development of a growth model for penaeid shrimp. Aquaculture 259, 268-277.

Fujiwara, T., L.P. Sanford, K. Nakatsuji, Y. Sugiyama, 1997. Anti-cyclonic circulation driven by the estuarine circulation in a gulf type ROFI. Journal of Marine Systems 12, 1-4.

Fulton E.A., D.M. Smith, and C.R. Johnson, 2003. Effect of complexity on marine ecosystem models. Marine Ecology Progress Series 253, 1-16.

Gangnery, A., Bacher, C., Buestel, D., 2004. Modelling oyster population dynamics in a Mediterranean coastal lagoon (Thau, France): sensitivity of marketable production to environmental conditions. Aquaculture 230, 323-347. 
GESAMP (IMO/FAO/Unesco-IOC/WMO/WHO/IAEA/UN/UNEP Joint Group of Experts on the Scientific Aspects of Marine Environmental Protection). 2001. Planning and management for sustainable coastal aquaculture development. GESAMP Reports and Studies, 68. 90pp.

Grant, J., Bacher, C., Cranford, P. J., Guyondet, T., Carreau, M., 2008. A spatially explicit ecosystem model of seston depletion in dense mussel culture. Journal of Marine Systems 73, 155168.

Greiner, R., 2004. Systems framework for regional-scale integrated modelling and assessment. Mathematics and Computers in Simulation 64, 41-51.

GRID-Geneva: Global Resource Information Database, Geneva office. 2004. FAO - UNESCO soil map of the world; 130 soil types (grid version). United Nations Environment Programme, Division of Early Warning and Assessment, Genebra. Available online at: www.grid.unep.ch/

Hardman-Mountford, N.J., Allen, J.I., Frost, M.T., Hawkins, S.J., Kendall, M.A., Mieszkowska, N., Richardson, K.A., Somerfield, P.J., 2005. Diagnostic monitoring of a changing environment: An alternative UK perspective. Marine Pollution Bulletin 50, 1463-1471.

Hawkins, A.J.S., Duarte, P., Fang, J.G., Pascoe, P.L., Zhang, J.H., Zhang, X.L. and Zhu, M.Y., 2002. A functional growth model of responsive suspension-feeding and growth in bivalve shellfish, configured and validated for the scallop Chlamys farreri during culture in China. J. Exp. Mar. Biol. Ecol. 281, 13-40.

Hofmann, J., Behrendt, H., Gilbert, A., Janssen, R., Kannen, A., Kappenberg, J., Lenhart, H., Lise, W., Nunneri, C., Windhorst, W., 2005. Catchment-coastal zone interaction based upon scenario and model analysis: Elbe and the German Bight case study. Regional Environmental Change 5, 54-81. Huang, D.W., Wang, H.L., Feng, J.F., Zhu, Z.W., 2008a. Modelling algal densities in harmful algal blooms (HAB) with stochastic dynamics. Applied Mathematical Modelling 32, 1318-1326.

Huang X.Q., Wang J.H., Jiang X.S., 2008b. Marine environmental capacity and pollution control in Xiangshan Gang. China Ocean Press. 348pp.

Huang S., H. Lou, Y. Xie, J. Hu, 2003. Hydrodynamic Environment and its effects in the Xiangshan Bay. International Conference on Estuaries and Coasts, November 9-11, 2003, Hangzhou, China.

Huppert, A., Blasius, B., Olinky, R., Stone, L., 2005. A model for seasonal phytoplankton blooms. Journal of Theoretical Biology 236, 276-290.

Hur H. B., G. A. Jacobs, W. J. Teague. 1999. Monthly Variations of Water Masses in the Yellow and East China Seas. Journal of Oceanography, vol. 55 pp 171-184. 
Isobe A., E. Fujiware, P. Chang, K. Sugimatsu, M. Shimizu, T. Matsuno, A. Manda, 2004. Intrusion of Less Saline Shelf Water into the Kuroshio Subsurface Layer in the East China Sea. Journal of Oceanography 60, 853-863.

James, I. D., 2002. Modelling pollution dispersion, the ecosystem and water quality in coastal waters: a review. Environmental Modelling \& Software 17, 363-385.

Kalnay E, Kanamitsu M, Kistler R, Collins W, Deaven D, Gandin L, Iredell M, Saha S, White G, Woollen J, Zhu Y, Chelliah M, Ebisuzaki W, Higgins W, Janowiak J, Mo KC, Ropelewski C, Wang J, Leetmaa A, Reynolds R, Jenne R, Joseph D. 1996. The NCEP/NCAR 40-year reanalysis project, Bull. Amer. Meteor. Soc. 77, 437-470.

LDEO, Lamont-Doherty Earth Observatory. 2008. IRI/LDEO Climate Data Library. The Earth Insititute, University of Columbia. Available online at: http://iridl.Ideo.columbia.edu/.

Ledoux, L., Beaumont, N., Cave, R., Turner, R. K., 2005. Scenarios for integrated river catchment and coastal zone management. Regional Environmental Change 5, 82-96.

Liang S., Qian H.L., Qi Y.Z., 2000. Problem on the Red Tide in Coastal China Sea. Ecological Science 19, 44-50.

Lillesand TM, Kiefer RW. 1999. Remote sensing and image interpretation. 4th edition. John Wiley \& Sons, New York.

Liu, D., Keesing, J. K., Xing, Q., Shi, P. World's largest macroalgal bloom caused by expansion of seaweed aquaculture in China. Marine Pollution Bulletin, In press, doi:10.1016/j.marpolbul.2009.01.013.

Liu, C.L., Chen, H.T., Ren, H.B., Zhang, G.S., 2003. Nutrient elements in wet deposition (precipitation) from the Yellow Sea and the East China Sea regions. Marine Environmental Science (China) 22, 26-30.

Long H., Zhou Y., Yu Y.F., Fu G.J., 2008. Analyses on harmful algal blooms in Zhejiang coastal waters from 2001 to 2007. Marine Environmental Science 27, S1-S4.

Marinov, D., Galbiati, L., Giordani, G., Viaroli, P., Norro, A., Bencivelli, S., Zaldivar, J. M., 2007. An integrated modelling approach for the management of clam farming in coastal lagoons. Aquaculture 269, 306-320.

McKindsey, C. W., Thetmeyer, H., Landry, T., Silvert, W., 2006. Review of recent carrying capacity models for bivalve culture and recommendations for research and management. Aquaculture 261, 451-462. 
Moll, A., Radach, G., 2003. Review of three-dimensional ecological modelling related to the North Sea shelf system. Progress in Oceanography 57, 175-217.

Murawski, S., Cyr, N., Davidson, M., Hart, Z., Noaa, Balgos, M., Wowk, K., Cicin-Sain, B., GLOBAL FORUM, 2008. Policy brief on achieving EBM and ICM by 2010 and progress indicators. 4th Global Conference on Oceans, Coast, and Islands: Advancing Ecosystem Management and Integrated Coastal and Ocean Management in the Context of Climate Change. April 7-11, 2008, Hanoi, Vietnam. 70p.

Murawski, S.A., 2007. Ten myths concerning ecosystem approaches to marine resource management. Marine Policy 31, 681-690.

National Standard of People's Republic of China, 1997. Sea water quality standard, GB3097-1997.

Neitsch, S.L., Arnold, J.G., Kiniry, J.R., Williams, J.R., Kiniry, K.W., 2002. Soil and Water

Assessment Tool theoretical documentation. TWRI report TR-191, Texas Water Resources Institute, College Station.

Nikolaidis, N.P., Karageorgis, A.P., Kapsimalis, V., Drakopoulou, P., Skoulikidis, N., Behrendt, H., Levkov, Z., 2009. Management of nutrient emissions of Axios River catchment: Their effect in the coastal zone of Thermaikos Gulf, Greece. Ecological Modelling 220, 383-396.

Ning, X.R., Hu, X.G., 2002. Aquaculture ecology and carrying capacity assessment in Xiangshan Harbour. Beijing: Ocean Press, pp92-93.

Ningbo Municipal People's Government, 2006. The Eleventh Five-Year Plan. Chapter VI. Accelerating the Advancement of Urbanization, and Promoting harmonious Progress of Different Areas. Available at http://english.ningbo.gov.cn/col/col450/index.html, last access at October 2008.

Nobre, A.M. An ecological and economic assessment methodology for coastal ecosystem management. Environmental Management, In press.

Nobre, A.M., Ferreira, J.G., 2009. Integration of ecosystem-based tools to support coastal zone management. Journal of Coastal Research SI 56, 1676-1680.

Nobre, A.M., Musango, J.K., de Wit M.P., Ferreira, J.G. A dynamic ecological-economic modeling approach for aquaculture management. Ecological Economics, In press.

Nobre A. M., J. G. Ferreira, A. Newton, T. Simas, J. D. Icely, R. Neves, 2005. Management of coastal eutrophication: Integration of field data, ecosystem-scale simulations and screening models. Journal of Marine Systems 56, 375-390. 
NOFB, Ningbo Ocean and Fisheries Bureau. 2007. Distribution plan of fish cages in Xiangshan Bay. 25pp.

Nunes, J. P., Ferreira, J. G., Gazeau, F., Lencart-Silva, J., Zhang, X. L., Zhu, M. Y., Fang, J. G., 2003. A model for sustainable management of shellfish polyculture in coastal bays. Aquaculture 219, 257-277.

Nunneri, C., Hofmann, J., 2005. A participatory approach for Integrated River Basin Management in the Elbe catchment. Estuarine, Coastal and Shelf Science 62, 521-537.

Plus, M., Chapelle, A., Lazure, P., Auby, I., Levavasseur, G., Verlaque, M., Belsher, T., DeslousPaoli, J.-M., Zaldivar, J.-M., Murray, C. N., 2003. Modelling of oxygen and nitrogen cycling as a function of macrophyte community in the Thau lagoon. Continental Shelf Research 23, 1877-1898.

Raick C., K. Soetaert, M. Grégoire, 2006. Model complexity and performance: How far can we simplify? Progress in Oceanography 70, 27-57.

Raillard, O., A. Ménesguen 1994. An ecosystem box model for estimating the carrying capacity of a macrotidal shellfish system. Mar. Ecol. Prog. Ser. 115, 117-130.

Rantajärvi, E., Olsonen, R., Hällfors, S., Leppänen, J. M., Raateoja, M., 1998. Effect of sampling frequency on detection of natural variability in phytoplankton: unattended high-frequency measurements on board ferries in the Baltic Sea. ICES J. Mar. Sci. 55, 697-704.

RSS, Remote Sensing Systems. 2008. Special Sensor Microwave/Imager (SSM/I) data products. Remote Sensing Systems, Santa Rosa. Available online at: http://www.ssmi.com/.

Roebeling, P.C., Bohnet, I., Smith, M., Westcott, D., Kroon, F., Hartcher, M., Hodgen, M., Vleeshouwer, J., 2005. Landscapes Toolkit for triple-bottom-line assessment of land use scenarios in Great Barrier Reef catchments. MODSIM 2005 International Congress on Modelling and Simulation.Modelling and Simulation Society of Australia and New Zealand, December 2005, 711717.

Salomons, W., Turner, K., 2005. Catchment-coastal region research. Regional Environmental Change 5, 50-53.

Simpson, J.H., 1997. Physical processes in the ROFI regime. Journal of Marine Systems 12, 1-4. SOA, State Oceanic Administration China. 2006. Annual report of marine environment quality in China. 75 pp. 
Sohma, A., Sekiguchi, Y., Kuwae, T., Nakamura, Y., 2008. A benthic-pelagic coupled ecosystem model to estimate the hypoxic estuary including tidal flat--Model description and validation of seasonal/daily dynamics. Ecological Modelling 215, 10-39.

Soto, D., Aguilar-Manjarrez, J., Hishamunda, N. (Editors), 2008. Building an ecosystem approach to aquaculture. FAO/Universitat de les Illes Balears Expert Workshop. 7-11 May 2007, Palma de Mallorca, Spain. FAO Fisheries and Aquaculture Proceedings. No. 14. Rome, FAO. 2008. 221p.

Volk, M., Hirschfeld, J., Dehnhardt, A., Schmidt, G., Bohn, C., Liersch, S., Gassman, P. W., 2008. Integrated ecological-economic modelling of water pollution abatement management options in the Upper Ems River Basin. Ecological Economics 66, 66-76.

Wang FB, 2002. The water pollution introduced by aquaculture using net-cage and countermeasures controlling of it. Marine Sciences (China) 26, 24-26.

Weise, A.M., Cromey, C.J., Callier, M.D., Archambault, P., Chamberlain, J., McKindsey, C.W., 2009. Shellfish-DEPOMOD: Modelling the biodeposition from suspended shellfish aquaculture and assessing benthic effects. Aquaculture 288, 239-253.

Wentz, F.J., Spencer, R.W., 1998. SSM/I Rain Retrievals within a Unified All-Weather Ocean Algorithm. Journal of the Atmospheric Sciences 55, 1613-1627.

Whalen, J., Uljee, I., White, R., Neis, B., Engelen, G., 2004. An individual based model of the lobster fishery in St. John Bay, Newfoundland, Canada, Research Institute for Knowledge Systems, Maastricht. 87pp.

Whitall, D., Bricker, S., Ferreira, J., Nobre, A., Simas, T., Silva, M., 2007. Assessment of Eutrophication in Estuaries: Pressure-State-Response and Nitrogen Source Apportionment. Environmental Management 40, 678-690.

WL|Delft-Hydraulics (1996). Delft3D-FLOW User Manual Version 3.05. Delft, Netherlands, WL|Delft Hydraulics, 614 pp.

Zhang, L.L., Jiang, X.S., Cai, Y.H., Li, Z.E., 2007. Comprehensive assessment of the situation of water quality at the red tide monitoring area of Xiangshan Harbor in recent four years. Transaction of Oceanology and Limnology 4, 98-103.

ZOFB, Zhejiang Ocean and Fisheries Bureau. 2008. Bulletin of Marine Environment in Zhejiang Province in 2007. pp40. 


\section{List of figures}

Figure 1. Xiangshan Gang and catchment area characterization.

Figure 2. Integrated catchment-bay modelling approach for coastal ecosystem management.

Figure 3. Catchment model outputs: simulated monthly runoff (compared with rainfall, top) and nitrogen loads from diffuse and point sources (bottom).

Figure 4. Standard simulation outputs for an inner box (Box 3, Huangdun Bay) and a middle box (Box 10), plotted with average daily data (June2005/June2006): phytoplankton biomass, dissolved inorganic nitrogen (DIN), phosphate, suspended particulate matter (SPM) matter and particulate organic matter (POM).

Figure 5. Standard simulation outputs for Box 3 (in grey) and Box 11 (in black) for: oyster production (standing stock, total biomass, harvesting); mass loss due to reproduction, faeces and excretion; and key environmental variables affecting oyster growth (phytoplankton biomass, particulate organic matter and water temperature).

Figure 6. Standard simulation outputs for shellfish harvest and comparison with data (in t year ${ }^{-1}$ ).

Figure 7. Scenario simulation outputs for an inner box (Box 3, Huangdun Bay), a middle box (Box 6), and an outer box (Box 12): dissolved inorganic nitrogen (DIN), phosphate, particulate organic matter (POM), phytoplankton biomass, harvested shellfish and shellfish productivity.

Figure 8 . Shellfish productivity expressed as the ratio of harvest biomass to seeding biomass.

Figure 9. Sensitivity analysis simulation plots for an inner box (Box 3, Huangdun Bay), a middle box (Box 6), and an outer box (Box 12): dissolved inorganic nitrogen (DIN), phosphate, phytoplankton biomass and particulate organic matter (POM). (Straight lines in the plots indicate average value for DIN and phosphate, and 90-Percentile for phytoplankton). 


\section{List of tables}

Table 1. Examples of modelling tools used for the application of legislation and management programmes worldwide.

\begin{tabular}{|c|c|c|}
\hline $\begin{array}{l}\text { Legislation / } \\
\text { management actions }\end{array}$ & Model application & $\begin{array}{l}\text { Country } \\
\text { / region }\end{array}$ \\
\hline $\begin{array}{l}\text { European Water } \\
\text { Framework Directive } \\
\text { (WFD, Directive } \\
2000 / 60 / \text { EC) }\end{array}$ & $\begin{array}{l}\text { Hofmann et al. (2005), Artioli et al. (2005) and Volk et al. } \\
(2008)\end{array}$ & Europe \\
\hline $\begin{array}{l}\text { CSIRO's Water for } \\
\text { Healthy Country } \\
\text { 'Floodplain renewal' } \\
\text { program }\end{array}$ & $\begin{array}{l}\text { 'Landscape toolkit' developed for the management of the } \\
\text { coastal strip adjacent to the Great Barrier Reef (Roebeling } \\
\text { et al., 2005) }\end{array}$ & Australia \\
\hline $\begin{array}{l}\text { USA National Estuarine } \\
\text { Eutrophication } \\
\text { Assessment (NEEA) } \\
\text { program }\end{array}$ & $\begin{array}{l}\text { Eutrophication assessment model (Bricker et al., 2003). Also } \\
\text { applied outside USA (Whitall et al., 2007; Borja et al., 2008). }\end{array}$ & $\begin{array}{l}\text { USA, } \\
\text { Europe } \\
\text { and } \\
\text { Asia }\end{array}$ \\
\hline $\begin{array}{l}\text { Fisheries policy } \\
\text { (management of the } \\
\text { exploitation of aquatic } \\
\text { renewable resources) }\end{array}$ & $\begin{array}{l}\text { - Lobster fishery simulation to explore management options, } \\
\text { regulations and the impact of environmental changes } \\
\text { (Whalen et al., 2004) } \\
\text { - Evolution of the Manila clam population in response to } \\
\text { different management measures and to exceptional } \\
\text { changes in environmental conditions (Bald et al., In press). }\end{array}$ & $\begin{array}{l}\text { Canada } \\
\text { and } \\
\text { France }\end{array}$ \\
\hline $\begin{array}{l}\text { Harmful algal blooms } \\
\text { (HAB's) management }\end{array}$ & $\begin{array}{l}\text { Combination of remote sensing data and current direction } \\
\text { simulation to understand the origin of the world's largest } \\
\text { green tide, recorded offshore in the Yellow Sea and along } \\
\text { the coast of Qingdao (Liu et al., In press). }\end{array}$ & China \\
\hline
\end{tabular}


Table 2. Synthesis of dataset used in the integrated modelling approach. Data source: SPEAR project (Ferreira et al., 2008b) unless indicated.

\begin{tabular}{ll}
\hline Domain & Parameters \\
\hline Catchment & River water quality data for years 2005/2006 (monthly sampling): ammonia, \\
area & nitrate, phosphate, silicate, total nitrogen, total phosphorus, chl-a, flow rate, \\
& temperature, salinity, pH, dissolved oxygen. \\
& Land cover ground truth data collected in 2005: Urban area, paddy fields, dry \\
& crop land, burnt land, forest, shrubby area, aquaculture, wetland, shallow \\
& water/beach, water and cloud. \\
& Landsat ETM+ images (2005/06/28), used to create landcover maps following \\
& a supervised classification approach (Lillesand and Kiefer, 1999). \\
& Hydrological data: precipitation, drainage area, river network. \\
& Topographic data collected during the Shuttle Radar Topography Mission \\
& (SRTM), with a resolution of 90x90 m (CGIAR, 2005); \\
& Biophysical and agricultural management parameters following the SWAT \\
& database for the most common crop (rice); \\
& Global Zobbler soil maps with a 2x2' (approx. 3.5x3.5 Km) resolution (GRID- \\
& Geneva, 2004), parameterized following Batjes (2002). \\
& Urban wastewater discharge, estimated from the number of inhabitants, using \\
& typical per capita wastewater and nutrient generation values (e.g. \\
& Economopoulos, 1993). \\
\hline
\end{tabular}

Meteorological Precipitation data for years 2000/2001 (Liu et al., 2003): total rainfall, / climate: ammonia, nitrate, nitrite, phosphate and silicate.

Daily rainfall data for years 2003/2006: remote sensing using the SSM/I F14 product (Wentz and Spencer, 1998; RSS, 2008).

Daily meteorology for years 2003/2006: NCEP/NCAR reanalysis for temperature, humidity, wind speed and solar radiation (Kalnay et al., 1996). Climatic normals: calculated using the climate data library maintained by LDEO (2008).

Sea boundary Water quality data for year 2002: Salinity, water temperature, ammonium, nitrate, nitrite, phosphate, dissolved oxygen, chl-a.

Bay Water quality data for years 2004 (bi-monthly) and Jun05/Jun06 (monthly):

(18 stations) Water height, depth, current velocity, water temperature, salinity, ammonia, nitrite, nitrite, organic nitrogen, phosphate, dissolved oxygen, chl-a, particulate organic matter and suspended particulate matter.

Aquaculture Shellfish individual growth experiments: responses in feeding and metabolism data $^{\mathrm{a}} \quad$ to different combinations of food composition, temperature and salinity Shellfish aquaculture production data: Individual seeding weight, seeding densities, population mortality, harvestable size, total harvest.

Finfish aquaculture for years 2004 and 2005: (i) Total production; and (ii) waste data (Cai and Sun, 2007).

Aquaculture structure mapping: Landsat visible and infra-red data (2005/06/28) and local maps for ground truthing and to detail smaller aquaculture structures.

a Spatially distributed aquaculture production data covers only the inner part of xiangshan Gang. Total production data was extrapolated for the remaining area based proportionally to the box area. 
Table 3. Main equations for catchment, hydrodynamic, aquatic resources and biogeochemical submodel state variables.

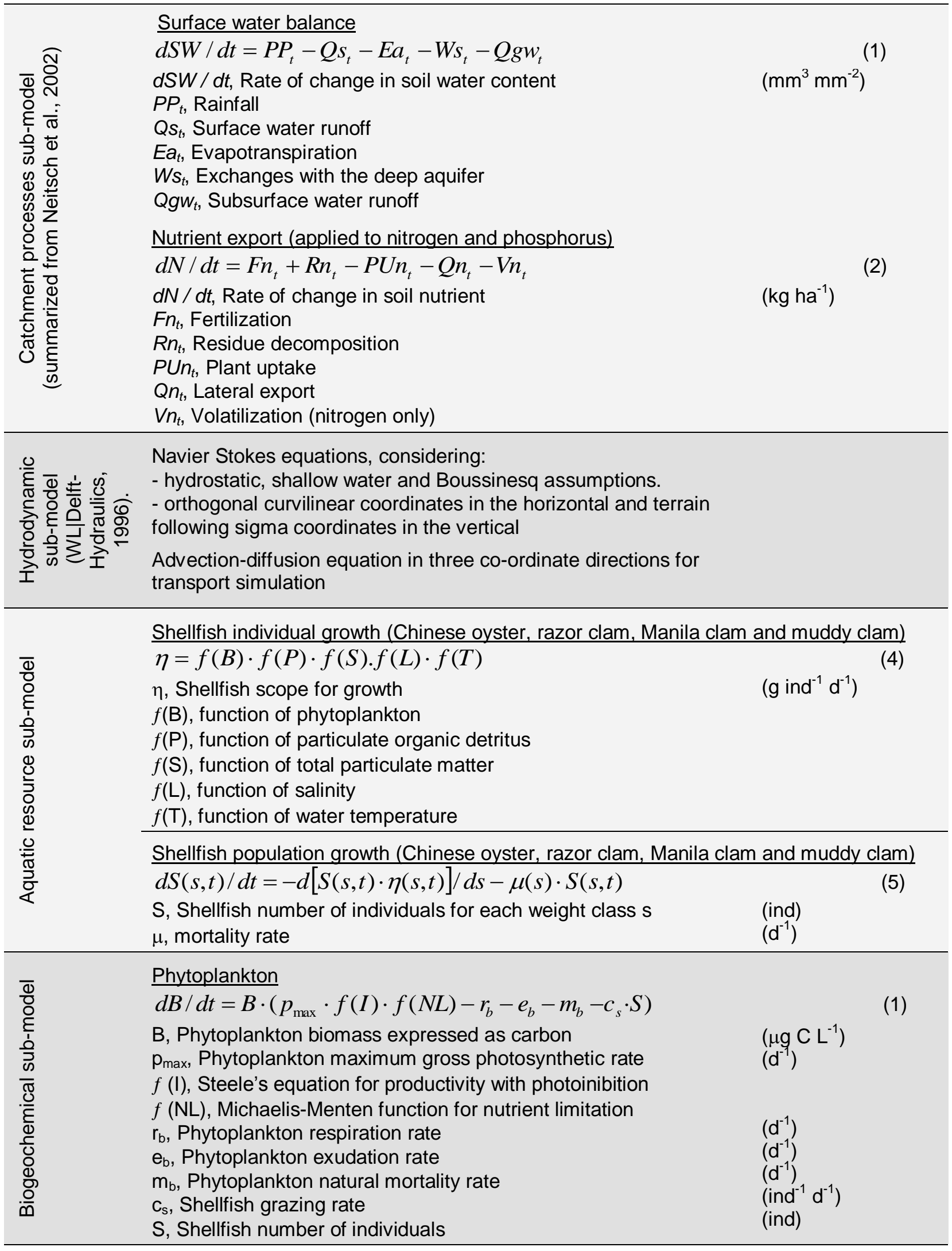


Dissolved inorganic nutrients (applied to nitrogen and phosphorus)

$d N / d t=\alpha \cdot B \cdot\left(e_{b}+m_{b}\right)+e_{s} \cdot S+\varepsilon \cdot P \cdot m_{p}-\alpha \cdot B \cdot\left(p_{\max } \cdot f(I) \cdot f(N L)\right)$

$\mathrm{N}$, Dissolved inorganic nutrient (nitrogen / phosphorus)

$\alpha$, Conversion from phytoplankton carbon to nitrogen units

$\left(\mu \mathrm{mol} \mathrm{L}{ }^{-1}\right)$

$\mathrm{P}$, Particulate organic matter (POM)

$\varepsilon$, Conversion from POM dry weight to nitrogen units

$\mathrm{m}_{\mathrm{p}}$, POM mineralization rate

$(-)$

$\left(\mathrm{mg} \mathrm{L}^{-1}\right)$

$\mathrm{e}_{\mathrm{s}}$, Shellfish excretion rate

$(-)$

$\left(d^{-1}\right)$

Particulate organic matter

$d P / d t=P \cdot\left(e_{p}+d_{p}\right)+f_{s} \cdot S-P \cdot\left(m_{p}+p_{s} \cdot S\right)$

$\mathrm{P}, \mathrm{Particulate}$ organic matter (POM)

$\mathrm{e}_{\mathrm{p}}, \mathrm{POM}$ resuspension rate

$\mathrm{d}_{\mathrm{p}}$, POM deposition rate

$f_{s}$, Shellfish faeces production

$\left(\mu \mathrm{mol} \mathrm{L}^{-1} \mathrm{ind}^{-1} \mathrm{~d}^{-1}\right)$

$\mathrm{p}_{\mathrm{s}}$, Shellfish POM filtration rate

$\left(\mathrm{mg} \mathrm{L}^{-1}\right)$

$\left(d^{-1}\right)$

$\left(d^{-1}\right)$

$\left(\mathrm{mg} \mathrm{L}^{-1}\right.$ ind $\left.^{-1} \mathrm{~d}^{-1}\right)$

(ind $^{-1} d^{-1}$ ) 
Table 4. Ecosystem model forcing functions for standard simulation.

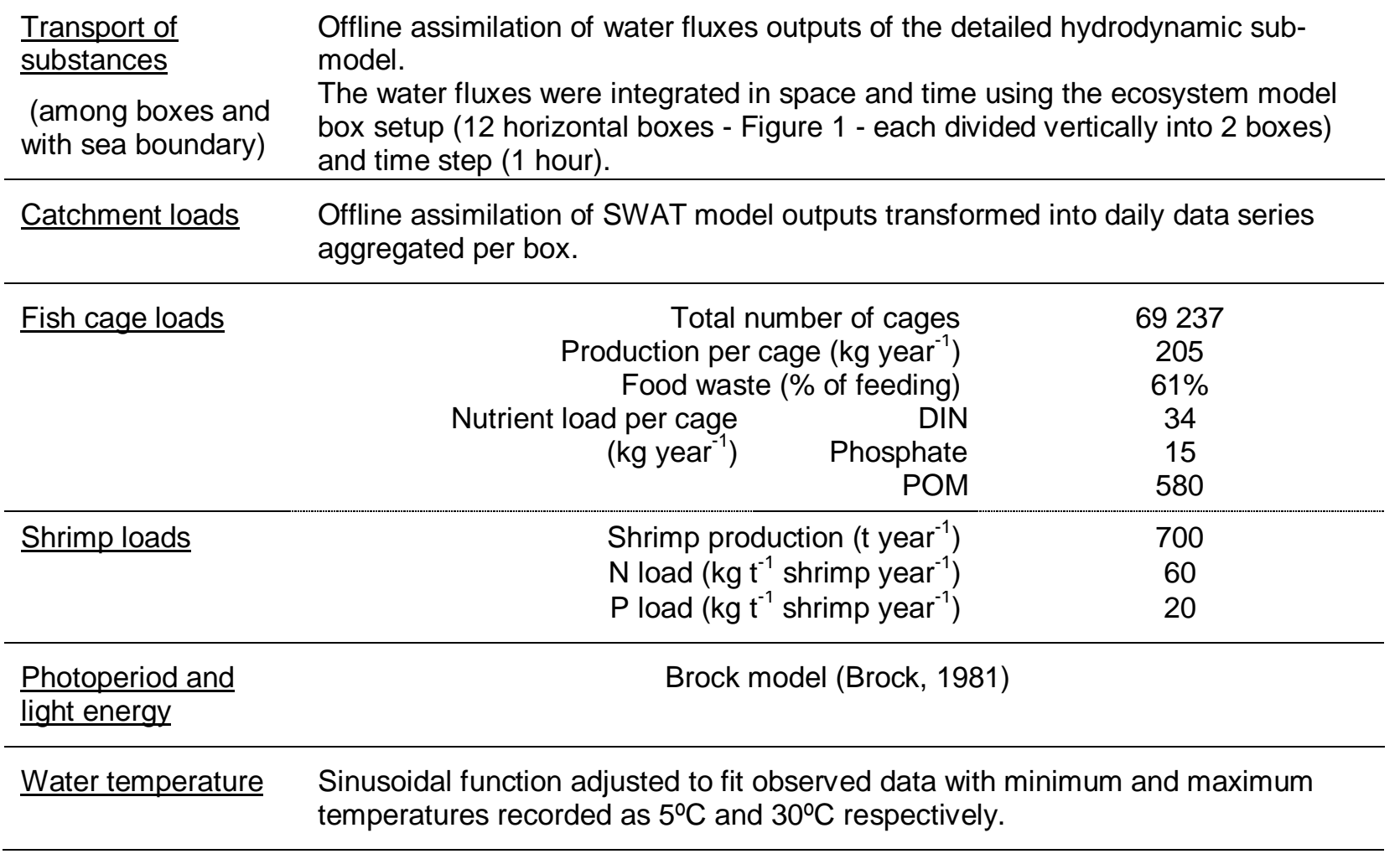


Table 5. Ecosystem model parameters for standard simulation.

\begin{tabular}{|c|c|c|c|}
\hline \multirow{5}{*}{$\begin{array}{l}\text { Shellfish } \\
\text { population }\end{array}$} & \multicolumn{2}{|c|}{ Number of weight classes } & \multirow{2}{*}{$\begin{array}{c}10 \\
0.40 \%\end{array}$} \\
\hline & Mortality & Oyster & \\
\hline & (\% per day) & Clam & $0.56 \%$ \\
\hline & & Razor & $0.20 \%$ \\
\hline & & Muddy & $0.15 \%$ \\
\hline \multirow{24}{*}{$\begin{array}{l}\text { Shellfish } \\
\text { cultivation } \\
\text { practice }\end{array}$} & \multirow{4}{*}{$\begin{array}{l}\text { Seed weight } \\
\left(g^{T} \text { TFW ind }{ }^{-1}\right)\end{array}$} & Oyster & 0.2 \\
\hline & & Clam & 0.5 \\
\hline & & Razor & 0.5 \\
\hline & & Muddy & 0.1 \\
\hline & \multirow[t]{4}{*}{ Seeding period } & Oyster & April - August \\
\hline & & Clam & May - June \\
\hline & & Razor & April - August \\
\hline & & Muddy & June - September \\
\hline & \multirow{4}{*}{$\begin{array}{r}\text { Harvestable } \\
\text { weight } \\
\left(\mathrm{g} \text { TFW ind }{ }^{-1}\right)\end{array}$} & Oyster & 8 \\
\hline & & Clam & 14 \\
\hline & & Razor & 11 \\
\hline & & Muddy & 5 \\
\hline & \multirow[t]{4}{*}{ Harvesting period } & Oyster & December - March \\
\hline & & Clam & January - February \\
\hline & & Razor & October - February \\
\hline & & Muddy & November - March \\
\hline & \multirow{2}{*}{$\begin{array}{r}\text { Aquaculture area } \\
\text { (ha) }\end{array}$} & Oyster & 2286 (Boxes 1 to $5,8,9,11,12$ ) \\
\hline & & Clam & 308 (Boxes 1 to 7, 10) \\
\hline & \multirow{2}{*}{$\begin{array}{r}\text { and boxes } \\
\text { cultivated }\end{array}$} & Razor & 313 (Boxes 1 to 6$)$ \\
\hline & & Muddy & 187 (Boxes 1 to $3,5,6)$ \\
\hline & \multirow{4}{*}{$\begin{array}{r}\text { Seeding density } \\
\left(\mathrm{t} \mathrm{TFW} \mathrm{ha}^{-1}\right)\end{array}$} & Oyster & 0.90 \\
\hline & & Clam & 0.45 \\
\hline & & Razor & 0.72 \\
\hline & & Muddy & 0.82 \\
\hline \multirow{5}{*}{$\begin{array}{l}\text { Phytoplankton } \\
\text { growth }\end{array}$} & & $\operatorname{Pmax}\left(h^{-1}\right)$ & 0.2 \\
\hline & & $\operatorname{lop}\left(\mathrm{w} \mathrm{m}^{-2}\right)$ & 300 \\
\hline & & th loss $\left(d^{-1}\right)$ & 0.01 \\
\hline & & $V\left(\mu \mathrm{mol} \mathrm{L}{ }^{-1}\right)$ & 1 \\
\hline & & $\left(\mu \mathrm{mol} \mathrm{L} L^{-1}\right)$ & 0.5 \\
\hline \multirow{3}{*}{$\begin{array}{l}\text { Suspended } \\
\underline{\text { matter }}\end{array}$} & \multicolumn{2}{|c|}{ POM mineralization rate $\left(d^{-1}\right)$} & 0.02 \\
\hline & \multicolumn{2}{|c|}{$\mathrm{POM}$ to nitrogen (DW to $\mathrm{N}$ ) } & 0.0519 \\
\hline & \multicolumn{2}{|c|}{$\mathrm{POM}$ to phosphorus (DW to $\mathrm{P}$ ) } & 0.0074 \\
\hline
\end{tabular}


Table 6. Scenario definition (percentage changes compared with standard simulation are shown in brackets and italics).

\begin{tabular}{|c|c|c|c|c|c|c|c|c|c|}
\hline Setup & & Standard & Scn 1 & $\operatorname{Scn} 2$ & Scn 3 & & & & \\
\hline No. fish cages & & 69237 & 42927 & 69237 & 42927 & $\square$ Catch & hment & $\square$ Fish cage & ather \\
\hline$\%$ of standard simula & ion & & $62 \%$ & $100 \%$ & $62 \%$ & $\mathrm{~g}^{100 \%}$ & & & \\
\hline $\begin{array}{l}\text { Treated wastewate } \\
\text { (million inhabitants }\end{array}$ & & 0 & 0 & 0.6 & 0.6 & 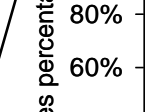 & & & \\
\hline $\begin{array}{r}\text { Total loads } \\
\left(\mathrm{t} \mathrm{d}^{-1}\right)\end{array}$ & DIN & 18.9 & $\begin{array}{r}16.2 \\
(-14 \%)\end{array}$ & $\begin{array}{l}17.5 \\
(-8 \%)\end{array}$ & $\begin{array}{r}14.7 \\
(-22 \%)\end{array}$ & 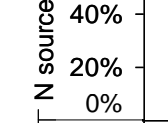 & & & \\
\hline Phospl & ate & 5.0 & $\begin{array}{r}3.9 \\
(-22 \%)\end{array}$ & $\begin{array}{r}4.2 \\
(-15 \%)\end{array}$ & $\begin{array}{r}3.1 \\
(-37 \%)\end{array}$ & 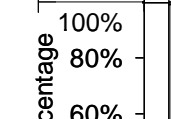 & & & \\
\hline & OM & 451.7 & $\begin{array}{l}410.1 \\
(-9 \%)\end{array}$ & $\begin{array}{r}413.8 \\
(-8 \%)\end{array}$ & $\begin{array}{l}372.1 \\
(-18 \%)\end{array}$ & 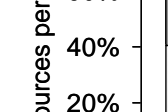 & & & \\
\hline Influencing Factors & $\mathrm{N}$ & $75 \%$ & $72 \%$ & $73 \%$ & $70 \%$ & $0 \%$ & & & \\
\hline & $P$ & $94 \%$ & $92 \%$ & $93 \%$ & $90 \%$ & & $\begin{array}{l}\frac{0}{0} \\
\frac{\pi}{0} \\
\frac{0}{5}\end{array}$ & : & 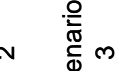 \\
\hline Boxes with chan & ges & & $\begin{array}{r}1-5,7- \\
12\end{array}$ & $\begin{array}{r}1,3,8,9 \\
, 12\end{array}$ & $\begin{array}{r}1-5,7- \\
12\end{array}$ & & & & \\
\hline
\end{tabular}

a The Influencing Factors comprise the catchment and aquaculture nutrient loads; this index (previously named Overall Human Influence, OHI) is calculated from Bricker et al. (2003) 
Table 7. Example of HAB events in Xiangshan Gang (ZOFB, 2008) and temporal evolution of HAB's in China (Liang et al., 2000; Long et al., 2008).

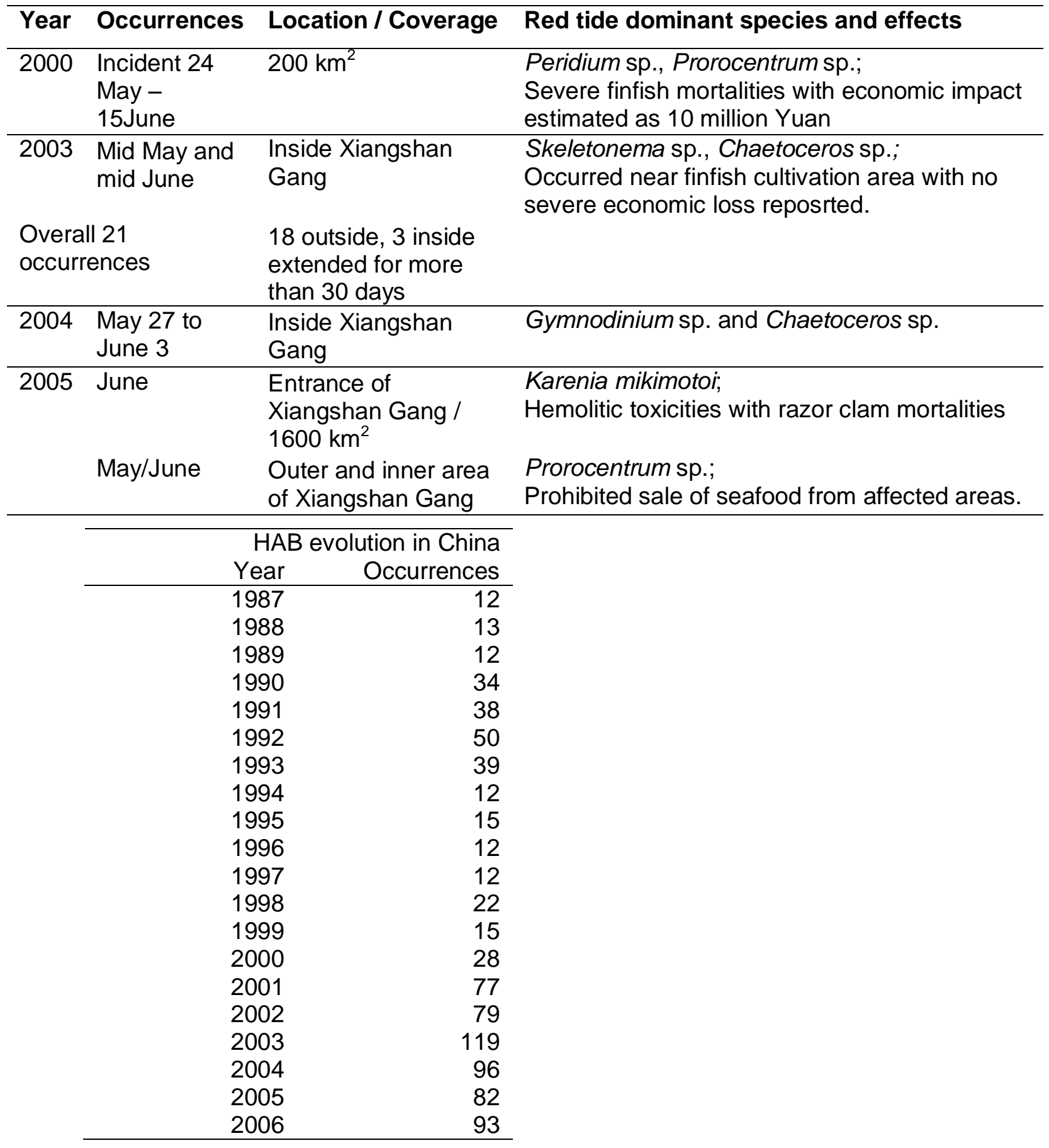

